\title{
Practicing Socialist Core Values to Improve Citizens' Moral Quality and Civilization Accomplishment*
}

\author{
Lihua Huang \\ Fuzhou University of International Studies and Trade \\ Fuzhou, China 350200
}

\begin{abstract}
Through the exploration and practice of socialist core values, this paper uses the new visual field, new requirements, and new realms of the socialist core value system to guide citizens' moral qualities and civilization accomplishment, and analyze the status quo of citizens' moral qualities and civilized qualities, so as to lay the foundation for the following research.
\end{abstract}

Keywords—socialist core values; moral quality; civilization accomplishment

\section{INTRODUCTION}

Since the reform and opening up, under the leadership of the socialist banner with Chinese characteristics, China has made brilliant achievements in its economic and social development and gradually formed a relatively complete theoretical system and core values on socialism with Chinese characteristics. In December 2013, the General Office of the CPC Central Committee issued the "Opinions on Cultivating and Practicing Core Socialist Values," and clearly stated that the socialist core values with "three advocacy" as the basic content should be in conformity with the requirements for the development of socialism with Chinese characteristics, in coincidence with the excellent traditional Chinese culture and the outstanding achievements of human civilization. This is an important conclusion made by China in bringing together the value consensus of the entire party and entire society. In 2015, General Secretary Xi Jinping stressed the routinization, concretization, visualization, and livelihood of socialist core values after the CICA Shanghai Summit. This is also the internal requirement for practicing socialist core values and improving the moral qualities and civilized qualities of citizens. The report of the 18th CPC National Congress clearly stated that it is necessary to vigorously advocate prosperity, democracy, civilization, harmony, promote freedom, equality, fairness, and the rule of law, advocate patriotism, dedication, honesty, and friendliness, and actively foster and practice the core values of socialism. In the report of the 19th National Congress of the Communist Party of China, it is stated that "we must cultivate and practice the core values of socialism, integrate socialist core values into all aspects of social development, and transform it into people's emotional identity and

*Fund Project: 2017 Key Projects of Research Center for Theoretical System of socialism with Chinese characteristics in Fuzhou: Practicing Socialist Core Values to Improve Citizens' Moral Quality and Civilization Accomplishment (2017A06) behavioral habits. We must strengthen ideological and moral construction, to make people have faith, the country has power, and the nation has hope." It emphasizes the importance of socialist core values and ideological and moral construction. In the crucial stage of building a well-off society in an all-round way, it is a "required course" to implement the socialist core values and promoting citizens' moral qualities and civilized qualities is a "lubricant." Therefore, practicing socialist core values and improving citizens' moral qualities and civilization qualities have important promotional values.

\section{ThE VAlue OF PRACTICING SOCIALIST CORE}

VALUES AND ENHANCING CITIZENS' MORAL QUALITY AND CIVILIZATION ACCOMPLISHMENT

- Practicing socialist core values, enhancing the study of citizens' moral quality and civilization accomplishment, and demonstrating the educational significance of socialist core values are conducive to enhancing the common ideological foundation of citizens. In today's society, diverse cultural trends are exchanging and mingling with each other, and there are also various value orientations. Therefore, there are inevitably some wrong trends of ideological trend, thoughts, and values that will make the boundaries of citizens' ideology unclear and the values ambiguous. What's more serious is they may make citizens lose their socialist orientation. If this situation exists, it will inevitably affect the stability and peace of society. The content of socialist core values embodies the essence of socialism with Chinese characteristics. Therefore, it not only has wide applicability and inclusiveness, but also has strong advancement and universality, so using it can enhance the common ideological foundation of citizens. All nations will move toward socialism, which is inevitable.

- Practicing socialist core values and promoting citizen's moral quality and civilization accomplishment not only point the way forward for the masses' thinking and overall development, but also lead to the realization of the Chinese dream of the great rejuvenation of the Chinese nation. Only when citizens master socialist core values and improve their moral qualities and civilization accomplishment can they lay the groundwork for 
future connection to practice, strengthen their beliefs in practice, nurture national pride in practice, and demonstrate the demeanor of the grassroots in practice. Therefore, the research results can provide reference for management department to make decision.

\section{REVIEW OF DOMESTIC AND FOREIGN RESEARCHES ON PRACTICING SOCIALIST CORE VALUES AND PROMOTING CITIZENS' MORAL QUALITY AND CIVILIZATION ACCOMPLISHMENT}

Foreign scholars have not made much research on socialist core values, and many of them analyze the concepts of dominant or mainstream values, such as Rokeach, Schwartz, and Hofstede. The domestic research results on the cultivation path of socialist core values are relatively abundant, mainly from the following aspects:

Guidance of ideological trend emphasizes using socialist core values to lead the construction of college network culture, campus culture and mass culture, firmly grasping the initiative of ideological and political education, and educating and guiding citizens to establish a correct outlook on life and values; value recognition analyzes the problems and causes of path misalignment of contemporary values recognition, puts forward the path to promote the recognition of core values. Conversion of practice believes that through daily, concrete, visualized, and life forms, we must work hard in learning, cultivation of morals, discrimination, and consolidation, consciously acknowledge and practice socialist core values; co-construction and sharing, is proposed to be socialist core values; improving the quality advocates to enhance citizen's cultural quality, moral quality, and comprehensive quality by using socialist core values; discourse support emphasizes the promotion of discourse power of socialist core values to tell Chinese stories well, spread Chinese voices, and interpret Chinese characteristics; mechanism innovation advocates innovation education and identification mechanism, research and guidance mechanism, practice and internalization mechanism, monitoring and safeguard mechanism, and assessment and incentive mechanism, to make socialist core values be recognized and consciously practiced. At present, the studies of practicing socialist core values and improving citizen's moral quality and civilization accomplishment are very messy. There is no recognized systematic and complete theoretical system.

\section{The Status of Practicing Socialist Core VALUES AND ENHANCING THE CITIZENS' MORAL QUALITY AND CIVILIZATION}

\section{A. Some Citizens' Moral Qualities and Civilization Accomplishment Are Not Strong Enough}

Citizens' moral quality and civilized culture are not strong. In the global tourism image assessment, Japanese tourists rank first and Chinese tourists rank third. According to surveys, Chinese tourists often give people the impression that they are of poor quality and unruly. In addition to spitting and other activities, there are the uncivilized behaviors such as "loud noise in public places". In public places such as hospitals, railway stations, and tourist attractions, uncivilized behaviors such as jumping a queue and squatting can often be seen. The public facilities will be broken after the installation for a period of time and cannot be used any more. These are the manifestations of lack of civic moral qualities and civilization accomplishment.

In the new era, China is a civilized country that is in line with modern civilization. Citizen is the main body of the country, and citizens' moral quality and civilization accomplishment are the source of their order. As philosophers say, the order of civilization not only comes from "rule" but also from "etiquette". After China entered a new period, all aspects have been developed and people's living standards have also been improved. However, many people have a misunderstanding that moral quality and civilization accomplishment are only personal matters, so they only need to take care of their own moral qualities and civilization accomplishment while other people's moral qualities and civilization accomplishment have nothing to do with them. This kind of thinking is wrong because moral quality and civilization accomplishment is the realization of the moral level and civilization of all humanity. It is not the problem of the moral quality and civilization accomplishment of a person, but the silence of citizens on moral quality and civilization accomplishment. Facing unethical and civilized behaviors, if we choose to turn a blind eye and let it go, it will only allow these behaviors to constantly erode the soil of morality and civilization.

\section{B. Some Citizens' Moral Quality and Civilization Accomplishment Are Not High}

On the issue of citizen's moral quality and civilization accomplishment, the recognition and self-consciousness of citizens' moral qualities and civilization accomplishment is a very realistic and fundamental issue. We all know that no matter what we do, the precondition for doing things well is that we must be serious. The citizen's sense of moral quality and civilization accomplishment are not high in today's society, and the uncivilized phenomenon in public places can be seen everywhere. In fact, this status quo has both historical features and features of a new era. Although China's traditional society has high moral requirements in terms of civilization, in the development process of China's traditional society from ancient times to modern times, our activities and production are based on the family and are all self-sufficient small-scale peasant economies. "Small farmer awareness" is actually the highest morality in the family. This is not a matter of a day or two, but the result of the lack of citizen's moral consciousness caused by the precipitation of several generations. The development of society in the new period has been accompanied by the establishment of a socialist market economy in China, which has transformed us from a small family to a big family. The present society is a society that embodies citizens' moral qualities and civilization accomplishment. In this context, family privacy and social morality are inevitable. This will inevitably lead to the phenomenon that people's moral quality and civilization accomplishment awareness are not high. 


\section{The Weakening of Some Citizens' Moral Qualities and Civilization Accomplishment}

The construction of some citizens' moral quality and civilization accomplishment are inextricably linked with moral quality education, and it is not possible that they do not involve moral quality education. It is also the most direct and core method to improve citizens' moral quality and civilization accomplishment through education. At present, China's education methods for citizens' moral qualities and civilization accomplishment are still relatively weak. Judging from the education received by universities, basically every student will take professional courses as the main learning goal, because we will eventually enter the society. Under the current social and market economy background, many students will think that major is our foundation. The important dependence on social values reflects the important embodiment of talent.

In cultivating talent, schools often focus on cultivating professional knowledge. They often neglect the cultivation of moral qualities and civilization accomplishment. In a fastpaced social life, citizens do not have much chance to receive moral education and civilization accomplishment, especially the embodiment of personal pursuing interests and individual values in some companies, let alone the education focusing on public moral qualities. They may not even establish a system for cultivating citizens' moral qualities and civilization accomplishment. In fact, a person who is fully beneficial to society must have outstanding personal qualities, and moral qualities and civilization accomplishment must be prominent. Otherwise, a complete outlook on life and ethics cannot be established. In the long run, this is very detrimental to the development of people. The weakening of citizens' moral quality and education of civilization accomplishment is an important reason for the moral quality and civilization accomplishment of Chinese citizens.

\section{Negative Influence of Cultural Infiltration and Bad Social Factors}

After China entered the era of rapid economic globalization, the link between it and other countries in the world has become more and more close, and there have been more and more civilized exchanges. In the era of globalization, some Western countries continue to disseminate their civilization to China in various forms, which poses a challenge to China's mainstream civilization. The foreign civilization have also infiltrated in various forms, affecting the establishment of Chinese citizens' world outlook, outlook on life and values, resulting in the influence on some Chinese citizens' morality and civilization accomplishment. The market economy is a developed commodity economy, which allocates resources through the supply and demand mechanism, price mechanism, and competition mechanism of market. Under the conditions of market economy, the material wealth of citizens has been greatly improved, but the single development of the market economy has had a negative impact on the moral quality and civilization accomplishment. Today's market economy has developed rapidly, but with the development of market economy, the construction of spiritual civilization, material civilization, political civilization, and ecological civilization cannot keep up with the development of market economy. In the context of market economy, people often neglect the public interest for the maximization of personal interests. For example, problems such as environmental pollution, lack of integrity such as counterfeit cigarettes, adulterated wine, and injected meat, and the jerry-built project all indicate that the single development of the market economy has caused a negative impact on public morals and civilization accomplishment.

\section{CONCLUSION}

Previous research results and existing research have laid a solid foundation for research in this area. However, existing studies mainly focus on the general laws of the ideological education process and are far from meeting citizens' needs for improving their moral quality and civilization accomplishment. It is difficult to meet the needs of systematic theory. Therefore, there are still many problems that urgently require the attention of the academic community, such as the less specific cultivation path of practicing socialist core values and improving the moral quality of civilization accomplishment. This is the significance of the further research in this field.

\section{REFERENCES}

[1] Liang Jiafeng et al. Analysis of the Path for the Education of Daily Life Rites Self-restraint and the Socialist Core Values[J]. Journal of Ideological \& Theoretical Education, 2017(2).

[2] Xiang Yuqiao. The Choice of Path for Cultivating and Practicing Socialist Core Values Choice [J]. Morality and Civilization, 2015(5).

[3] Zhang Fengzhi. Analysis of the Cultivation Path of Socialist Core Values [J]. China Newspaper Industry, 2017(8). 